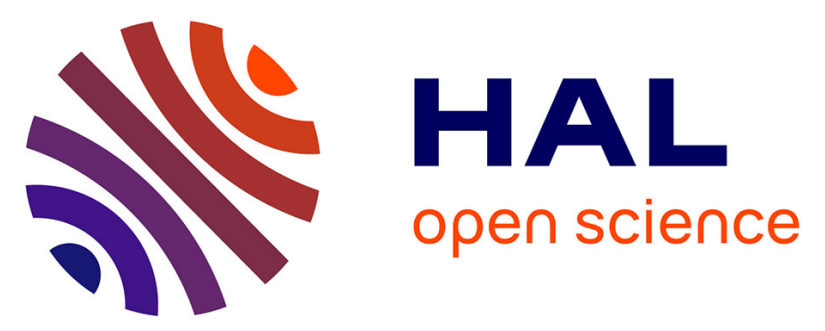

\title{
Differential atrial performance at rest and exercise in athletes: Potential trigger for developing atrial dysfunction?
}

L. Gabrielli, B. Bijnens, C. Brambila, Nicolas Duchateau, J. Marin, I. Sitges-Serra, L. Mont, J. Brugada, M. Sitges

\section{To cite this version:}

L. Gabrielli, B. Bijnens, C. Brambila, Nicolas Duchateau, J. Marin, et al.. Differential atrial performance at rest and exercise in athletes: Potential trigger for developing atrial dysfunction? Scandinavian Journal of Medicine and Science in Sports, 2016, 26 (12), pp.1444-1454. 10.1111/sms.12610 . hal-02282403

\section{HAL Id: hal-02282403 \\ https://hal.science/hal-02282403}

Submitted on 11 Sep 2019

HAL is a multi-disciplinary open access archive for the deposit and dissemination of scientific research documents, whether they are published or not. The documents may come from teaching and research institutions in France or abroad, or from public or private research centers.
L'archive ouverte pluridisciplinaire HAL, est destinée au dépôt et à la diffusion de documents scientifiques de niveau recherche, publiés ou non, émanant des établissements d'enseignement et de recherche français ou étrangers, des laboratoires publics ou privés. 
Differential atrial performance at rest and exercise in athletes: potential trigger for developing atrial dysfunction?

Luigi Gabrielli, MD ${ }^{1,2}$; Bart H Bijnens, PhD ${ }^{3,4}$; Carlos Brambila, MD ${ }^{1}$; Nicolas Duchateau, PhD ${ }^{1,3}$; Josefa Marin, RN ${ }^{1}$; Ignacio Sitges-Serra, MD ${ }^{1}$; Lluis Mont, MD,PhD ${ }^{1}$; Josep Brugada, MD,PhD ${ }^{1}$; Marta Sitges, MD,PhD ${ }^{1}$

${ }^{1}$ Thorax Clinic Institute, Hospital Clínic, ^IDIBAPS, University of Barcelona, Spain.

^IDIBAPS-Institut d'Investigacions Biomèdiques August Pi i Sunyer.

${ }^{2}$ Advanced Center for Chronic Diseases. Escuela de Medicina. Pontificia Universidad Católica de Chile, Santiago, Chile

${ }^{3}$ Universitat Pompeu Fabra, Barcelona, Spain.

${ }^{4}$ ICREA, Barcelona, Spain.

${ }^{5}$ Consell Catala de I'Esport, Barcelona, Spain.

Running Head: Atrial function in highly training athletes.

Word count: 3653

Address for correspondence: Marta Sitges, MD, PhD

Cardiology Department; Thorax Institute, Hospital Clínic

Villarroel 136, 08036 Barcelona, Spain

Phone \# 34- 93- 227 9305; Fax \# 34- 93- 4514148

E-mail: msitges@clinic.ub.es

Luigi Gabrielli, MD.

Pontificia Universidad Católica de Chile

Marcoleta 367, 8330024 Santiago, Chile

Phone \# 56-2-23543633; Fax \# 56-2-26338574

E-mail: Igabrielli@med.puc.cl 


\section{Abstract}

Background: Highly trained athletes show an increased risk of atrial arrhythmias. Little is known about atrial volumes and function during exercise in this population. Our aim was to analyze atrial size and function during exercise.

Methods: 50 endurance athletes with $11 \pm 8$ hours of training per week and 30 sedentary control subjects were included. Echocardiography was performed at baseline and during exercise. Left (LA) and right atrial (RA) size and function were assessed by two-dimensional echocardiography. Peak negative strain (Sa) during atrial contraction and active atrial emptying volume (AEV) were measured.

Results: Athletes and control subjects showed a significant increment of deformation and AEV of both atria with exercise ( $p<0.01$ vs baseline for LA and RA). Among athletes, a subgroup with significant $L A(n=8) / R A$ $(n=15)$ dilatation $\left(\geq 40 \mathrm{~mL} / \mathrm{m}^{2}\right)$ showed a significantly lower increment in AEV with exercise (LA $\triangle A E V: 1.4 \pm 1.1 \mathrm{~mL} / \mathrm{m}^{2}$ vs. $2.1 \pm 0.9 \mathrm{~mL} / \mathrm{m}^{2}, \mathrm{p}=0.04 ; \mathrm{RA} \triangle \mathrm{AEV}: 0.9 \pm 0.8 \mathrm{~mL} / \mathrm{m}^{2}$ vs. $\left.2.3 \pm 1.1 \mathrm{~mL} / \mathrm{m}^{2}, \mathrm{p}<0.01\right)$ and lower increment in deformation versus other athletes (LA $\Delta$ Sa:- $3.2 \pm 2.9 \%$ vs. $-9.5 \pm 4.4 \%, p<0.01 ; R A \Delta S a:-$ $2.5 \pm 3.3 \%$ vs. $-9.8 \pm 3.3 \%, p<0.01)$.

Conclusion: During exercise, active atrial strain increases, but less in athletes compared to controls, but due to larger atrial volumes, they reached similar increases in atrial emptying volume. However, this overall lesser deformation increases from a subgroup with significant atrial dilatation showing impairment in atrial contractile reserve.

Key words: atrial function, athletes, imaging stress test, atrial arrhythmia. 


\section{INTRODUCTION}

Highly trained athletes show an increased prevalence of atrial fibrillation (AF) as compared to casematched controls from the general population (Molina, 2008; Wilhelm, 2012a). Indeed, a meta-analysis of several observational studies reported a five-fold increase in the overall risk of AF in athletes (Abdulla, 2009). The etiology of the higher risk of arrhythmia in this particular group of subjects is still poorly understood (Wilhelm, 2012b; Wilhelm, 2012c). Atrial remodeling is actually a highly frequent finding among endurance athletes (Pelliccia, 2005). In this population, left ventricular filling occurs at early diastole at rest (D'Ascenzi, 2011), but active atrial function is particularly stressed and is a fundamental contributor to cardiac function during exercise (Gabrielli, 2014; Kusunose 2012). Accordingly, atrial function and volume are closely related to functional capacity during exercise (Naoum 2012; Vaturi 2010) and impairment of its contribution leads to a reduced exercise capacity (D'Andrea 2009). Atrial myocardial deformation as depicted by atrial strain and strain-rate analysis by two-dimensional speckle tracking has emerged as a novel method to evaluate left atrium (LA) (Saraiva, 2010) and right atrium (RA) function (Padeletti, 2012). These deformation imaging tools have been useful in different clinical scenarios such as pulmonary vein ablation (Schneider, 2008), coronary artery by-pass grafting (Gabrielli, 2011) and athlete's heart (Gabrielli, 2012). Moreover, simple computational models showed an inverse relationship between myocardial deformation and chamber size at a determined contractile performance (Bijnens, 2012).

The performance of the atria during exercise may provide insights into the mechanism underlying the development of atrial remodeling and this elevated risk of atrial arrhythmias. We have previously shown, in a subgroup of highly trained athletes at rest, significantly higher atrial volumes and lower deformation during active atrial contraction (Gabrielli, 2014). These particular working conditions potentially provide more atrial contractile reserve, but at the cost of higher atrial wall stress. However, little is known about atrial size and function during exercise in highly trained athletes. Especially the question, whether individuals with large atria and little active deformation during rest, are able to exploit their potential 
contractile reserve (Gabrielli, 2014) during exercise, is key to understand whether excessive atrial dilatation is beneficial or potentially detrimental in highly trained individuals.

According to this, the objective of the present study was to analyze the performance of both atria at rest and during exercise in a group of highly trained athletes, as quantified by relating myocardial deformation and size with a special focus on the performance of individuals with the most dilated atria.

\section{METHODS}

\section{Study design and population}

This was a cross-sectional study comparing two groups: 50 athletes and 30 sedentary healthy controls with similar age (mid thirties), who were recruited among hospital staff and patients' relatives with a strictly normal medical record. All participants were male, in sinus rhythm, normotensive, did not have any other cardiovascular risk factor and had normal echocardiography findings. The athletes group consisted of competitive marathon runners and and triathletes. All of them had been training an average of 12 hours/week during the past year, and in particular they had performed swimming, long distance running and cycling at workloads of $70 \%$ to $90 \%$ of theoretical maximal heart rate. All the subjects in the control group did not participate in any routine competitive or recreational sports. The ethics committee of our institution approved the study and informed consent was obtained from all individuals.

\section{Echocardiography}

A two-dimensional echocardiographic study using a commercially available ultrasound scanner (Vivid-Q, GE Healthcare, Milwaukee, WI) with a $2.5-\mathrm{MHz}$ phased array transducer (M4S) was performed in all subjects at baseline and during exercise. Standard echocardiographic views were obtained, including parasternal long and short axis, as well as apical two and four chamber views. Particular care in the acquisition of atrial images was taken. Frame rates were at least $60 \mathrm{~Hz}$ for two dimensional images. Stress echocardiography 
was performed with an ergometric supine bicycle and images were acquired at maximum exercise (previous to fatigue). The maximum exercise tolerance was expressed in Watts and estimated by metabolic equivalents (METs) and $\mathrm{O}_{2}$ consumption $(\mathrm{mL} / \mathrm{Kg} / \mathrm{min})$.

Images were analyzed offline with commercially available software (EchoPac version 108.1.6, GE Healthcare, Milwaukee, WI). LV and right ventricle (RV) size measurements were done according to the recommendations of the American Society of Echocardiography (Lang, 2006). LA volume was calculated from apical four and two-chamber views using the biplane method summation of discs (MacClean, 2014) and RA volume was measured from the apical four chamber view. LA and RA volumes were measured at three instants: (i) just before the opening of the mitral valve (maximum volume), (ii) at pre-atrial (A) contraction volume, obtained at mid-diastole at the beginning of the $P$ wave on surface electrocardiogram., and (iii) at the minimum volume just at the closure of the mitral valve. Atrial active emptying volume (AEV) was estimated as the difference between the pre A-wave volume and the minimum atrial volume and was used as a surrogate for stroke volume produced by atrial contraction. (Atrial active emptying fraction) AEF was calculated using the formula: (pre-A wave volume - minimum volume)/pre A-wave volume. Absolute differences between rest and exercise parameters were also calculated. Cardiac chamber size measurements were indexed by the body surface area. All data were analyzed by blinded, experienced sonographers. All measurements were done at baseline and during exercise. Significant LA dilatation was defined using a cut-off volume of $40 \mathrm{ml} / \mathrm{m}^{2} \quad$ (Lang, 2006) and arbitrarily the same value for RA.

\section{Atrial strain and strain rate}

Strain and strain rate of both atria were analyzed offline with a commercially available software package (2Dstrain, EchoPac version 108.1.6) from images acquired in the four-chamber view. The endocardial border was manually traced using a point-and-click technique. For speckle tracking analysis, we selected images with at least 60 frames/sec (Gabrielli, 2014). LA and RA active strains (LA negative peak strain during atrial contraction (LASa) and RA negative peak strain during atrial contraction (RASa), respectively) 
were calculated with the reference point set at the onset of the P-wave of the surface ECG (Rimbaş, 2014), which allowed identifying the peak negative strain (active shortening) during atrial contraction (Figure 1) Similarly, in the strain-rate curve we identified the peak negative strain rate (active shortening) during atrial contraction and the peak positive strain rate (stretching) during ventricular contraction in each atrium (LA negative peak strain rate during atrial contraction (LASRa) and RA negative peak strain rate during atrial contraction (RASRa), respectively). The software divided the atrial wall into 6 segments and the average was taken for analysis. Segments in which inadequate tracking was observed were excluded from further analysis and the remaining segments were averaged. Analysis was done at rest and during exercise (Figure 1).

\section{Statistical methods}

Continuous baseline variables were expressed as mean \pm standard deviation (SD) values or median (interquartile range), after checking for normal distribution as assessed by the Kolmogorov-Smirnov test. Categorical variables were expressed as total number (percentages) and compared between groups using Chi-square or Fisher's test when appropriate. Depending on the normality of the distribution, continuous variables were tested by unpaired T-test or Mann-Whitney U-test (unpaired data) and by paired T-test or Wilcoxon analysis (paired data). Complementarily, statistical differences in exercise response were assessed by mixed factorial ANOVA, where time (rest/exercise) is the within-subject factor, and group (control/athlete) is the between-subject factor. Box's test was used to control the homogeneity of variances. Pearson or Spearman methods were used to analyze the correlation between continuous variables when suitable. Intra-and inter-observer reproducibility was assessed using Bland-Altman analysis, on 10 different sequences/subjects for each strain and strain rate parameter by two different observers, respectively. Statistical significance was established at $p<0.05$. All data were analyzed using the SPSS version 15.0 (SPSS, Inc., Chicago, IL). 


\section{RESULTS}

\section{Population characteristics}

All subjects were male, and the two populations had similar age ( $37 \pm 6$ [athletes] vs. $35 \pm 4$ [controls] year old, $\mathrm{p}=$ non significant [NS] $)$ and body surface areas $\left(1.9 \pm 0.1 \mathrm{~m}^{2}\right.$ [athletes] vs. $1.9 \pm 0.2 \mathrm{~m}^{2}$ [controls], $\mathrm{p}=$ NS). The average athletes' training story was of $12 \pm 7$ years at the moment of the study.

Hemodynamic parameters at rest and during exercise in both groups are summarized together with ventricular performance in Table 1. As previously anticipated, athletes showed significantly higher oxygen consumption and reached higher METs and exercise load as compared to controls.

LV and RV dimensions were significantly larger in athletes as compared to controls at baseline (rest). During exercise, both groups showed a significant decrease in LV and RV volumes. LV ejection fraction and $\mathrm{RV}$ fractional area change were similar at rest and during exercise in both groups.

\section{LA and RA dimensions and function at rest and during exercise.}

Table 2 summarizes all the data regarding LA and RA dimensions and function at rest and during exercise in both groups. Athletes showed significantly higher LA volumes, including active emptying volume, at rest and during exercise as compared to controls. Additionally, both athlete and control groups showed a significant increment in LA active emptying volume and a significant decrease in LA volumes with exercise. Regarding LA deformation parameters, LASa and LASRa were similar among athletes and controls at rest, but significantly lower in athletes during exercise. A similar behavior regarding RA volumes and deformation parameters was observed among athletes and controls.

Figure 2 (A-D) depicts the interplay between atrial volume and deformation both for the LA and RA, through individual changes with exercise. Athletes globally showed a lower increment of atrial deformation parameters with exercise, $(\Delta \mathrm{LASa}=-8.4 \pm 4.8 \%$ [athletes] vs. $-12.2 \pm 4.5 \%$ [controls], $p<0.01 ; \Delta \mathrm{LASRa}=-1.28$ $\pm 1.03 \mathrm{~s}^{-1}$ [athletes] vs. $-1.76 \pm 0.74 \mathrm{~s}^{-1}$ [controls], $\mathrm{p}=0.03 ; \Delta \mathrm{RASa}=-7.2 \pm 4.8 \%$ [athletes] vs. $-10.3 \pm 3.9 \%$ [controls], $p=0.01 ;$ and $\triangle R A S R a=-0.79 \pm 0.69 \mathrm{~s}^{-1}$ [athletes] vs. $-1.11 \pm 0.72 \mathrm{~s}^{-1}$ [controls], $p=0.07$ ). In terms of 
group*exercise interaction, significant differences were observed for both LASa and LASRa $(p=0.001$ and $p=0.037$, respectively). Tests could not be performed on RASa as equality of variances cannot be assumed $(\mathrm{p}<0.001$ in Box's test), and RASRa returned non-significant differences. However, when athletes with significant LA dilatation i.e. LA volume $\geq 40 \mathrm{~mL} / \mathrm{m}^{2}$ (right part of Figure $2 \mathrm{~A}$ and $2 \mathrm{C}$ ) were excluded from the analysis $(n=8)$, no significant differences were observed between athletes and controls regarding the increase in LASa and LASRa during exercise ( $p=N S$, for both). The same observation was obtained excluding athletes with RA volume $\geq 40 \mathrm{~mL} / \mathrm{m}^{2}(\mathrm{n}=15)$ (right part of Figure $2 \mathrm{~B}$ and $2 \mathrm{D}$ ): no significant differences were observed between athletes and controls in the increase of RASa and RASRa during exercise ( $p=$ NS, for both).

\section{Subgroup of athletes with significant LA/RA atrial dilatation}

Figures 3, A-F show changes in atrial active deformation and atrial active emptying volume under the effect of exercise, in athletes with and without significant atrial dilatation. The subgroup of athletes with severely enlarged atria showed significantly less atrial deformation at rest and during exercise and a significantly lower increment during exercise, as compared to athletes without significant atrial dilatation [Figures $3 \mathrm{~A}$ and 3 C for LA (8 subjects with significant LA dilatation); Figures 3B and 3D show the same data for the RA (15 subjects with significant RA dilatation). This subgroup also showed a significantly lower increment of atrial active emptying volume during exercise as compared to athletes with smaller atria (Figures $3 \mathrm{E}$ and 3F). All subjects with significant LA dilatation $(n=8)$ showed also significant RA dilatation $(n=15)$.

Finally, a modest, but statistically significant correlation between reached METs during the exercise test and LA active emptying volume at rest and during exercise among the studied population were found (Figure 4)

\section{Quality of the speckle tracking procedure.}

Appropriate wall tracking (corresponding to low drift artifacts, as indicated by the software interface) was obtained in $97.5 \%$ of the segments evaluated at rest (LA and RA), in $93.7 \%$ of the LA and in $92.2 \%$ of the RA 
segments during exercise. Animated sequences of the speckle tracking output at rest and during exercise, illustrate the tracking quality on a concrete example are available as Supplementary data.

Reproducibility of the measurements (LA and RA, strain and strain rate, at rest and during exercise) is represented in Figure 5 (intra-observer agreement) and Figure 6 (inter-observer agreement) as BlandAltman plots. In both we showed a good agreement.

\section{DISCUSSION}

The present study showed that: (i) at rest, highly trained athletes had more dilated atria (both LA and RA), showed similar active atrial deformation parameters but an increased atrial active ejection volume, as compared to control subjects; (ii) athletes and controls showed a significant increment in atrial deformation parameters and active emptying volume during active atrial contraction with exercise; (iii) a subgroup of athletes, with significant atrial dilatation, showed lower increment in deformation parameters with exercise together with a significant lower increment in active emptying volume as compared to athletes with smaller atria. Moreover, the significant correlation found between atrial active emptying volume and exercise performance, supports the importance of atrial function and its response during exercise. These findings are in agreement with those of Kusunose (2012), who showed an independent association of LA function with exercise capacity in patients with preserved ejection fraction.

\section{Atrial remodeling}

While more data has been reported on the LV performance of athletes, atrial dimensions and function are scarcely studied in this population (Pluim, 2000). Previous echocardiographic reports, including endurance and non-endurance athletes have showed that LA dilatation (assessed with determination of the anteroposterior diameter of the LA) is common among athletes, but no relationship with supraventricular arrhythmia development was found (Pelliccia, 2005), in fact atrial mechanical function at rest is preserved 
in this population (Brugger, 2014). However, more recent experimental and clinical reports including endurance athletes have indeed shown an association between atrial remodeling and atrial arrhythmia development in the long-term follow-up (Benito, 2011; Mont, 2009; Van Buuren, 2012).

The atrial remodeling observed in athletes is an adaptive mechanism to the exposed volume overload (D'Andrea 2010; Voeller, 2011) with the objective of supporting the increased demand in cardiac output, and probably a mild or moderate remodeling process represents a physiologic and benign response in the vast majority of subjects (D'Andrea, 2010). However, this leads to different atrial working conditions at rest and during exercise, with less deformation and larger volumes, which potentially provides a better functional reserve but also results in an increased atrial wall tension, particularly in the subgroup with larger atrial volumes (Gabrielli, 2014). We have previously demonstrated this increased atrial wall stress with computer models that assumed that deformation increased with exercise (Gabrielli, 2014); the present work further supports our previous findings in confirming that atrial deformation actually increases during exercise both in controls and athletic subjects. In fact, elevated wall stress is an important risk factor for the initiation/worsening of myocardial damage (Marciniak, 2007; Di Martino, 2011). On the longer run, this atrial dysfunction derived from excessive atrial adaptation (remodeling) might result in increased vulnerability to atrial arrhythmias, through increased wall stress triggering atrial myocardial stretching and fibrosis (Margreet, 2010; Tsai, 2011). These findings are also consistent with observations on experimental animal models. In a rat model of long-term intensive exercise training, atrial fibrosis was demonstrated to be associated with an increased inducibility of atrial arrhythmia (Benito, 2011). However, further experiments on a dedicated study that include contractility would be necessary for a better assessment of atrial wall stress.

\section{Significant atrial dilatation: atria already in trouble?}

Additionally, we also identified a subgroup of endurance athletes with a significantly more advanced atrial remodeling process and evidence of contractile dysfunction. In our study population, using biplane indexed atrial volume we found that $30 \%$ of mid-thirties marathon runners showed significant RA dilatation and 
$16 \%$ significant LA dilatation, as defined by a reference cut-off point of $40 \mathrm{ml} / \mathrm{m}^{2}$ (Lang, 2006); moreover a subgroup of these subjects had severe atrial dilatation according to recently published guidelines (Lang, 2015). Our study showed a different active atrial deformation pattern and exercise response among these athletes. These observations add relevant information about the atrial remodeling process that is more pronounced in this subgroup of athletes and could potentially translate into a substrate for future atrial arrhythmias, and not only a physiological adaptation mechanism of LV filling process. In order to confirm this hypothesis, a long-term follow-up study is needed, especially in this particular subgroup of athletes. The reason why other athletes, with similar training loads, showed only modest atrial remodeling warrants further investigation. These individuals may probably have their own threshold for potential atrial myocardial damage in a dose-dependent (exercise load) fashion (O'Keefe, 2012).

Another important issue concerns the higher remodeling observed for the right atrial chamber with respect to the left one. This is in agreement with other observations of more pronounced structural remodeling of right-sided cardiac chambers in endurance athletes (La Gerche, 2012; D’Ascenzi, 2013).

\section{Limitations}

One limitation of our study was the lack of a strict homogenization of athletes' population regarding their training intensity and performance, which could help in the identification of the subjects with the biggest risk of atrial remodeling. The impact of different body sizes was normalized by indexing cardiac dimensions by body surface area; however, it is well recognized that this may not fully counteract the effect of absolute atrial myocardial mass, a factor that has been also related to the occurrence of atrial fibrillation (Mont, 2008). Moreover, the changes in atrial performance that we observed could not be extrapolated to other forms of cardiac loading rather than supine bicycle and the maximal oxygen consumption reached could be underestimated due to discomfort in doing exercise in the supine bicycle.

Another limitation, inherent from the use of echocardiographic parameters, is the reproducibility of atrial strain measurements particularly during exercise. Additionally, current speckle tracking tools may perform worse when applied to the right side of the heart and the atria, and during exercise, specially due to the 
lower temporal resolution, the lower quality of the images, and possible a-priori design of the algorithms for the left ventricle; however we believe it is based in principles that can be applied to atrial function assessment (Behar, 2004). Also we paid special attention to the correct tracking of the images and we have also reported the feasibility and reproducibility of our measurements, with adequate intra- and interobserver variability. Consequently, we believe that these measurements are reliable provided the observer takes the time to verify frame-by-frame that the proposed tracking actually follows the wall seen in the echocardiographic image, and that the deformation values actually reflect what is seen in the image. Animated figures showing a concrete example of the tracking quality at rest and during exercise are available as Supplementary data. We used optimized views to perform our reproducibility study, and, despite the same loops were used to repeat measurements, all endocardial traces were re-traced from scratch, blinded to the previously done segmentations in a different frame image. A reliability study that includes sequences taken at different times could add more confidence to the method, and perhaps the concomitant use of tissue Doppler imaging.

The assessment of atrial myocardial deformation was only performed from images in the four-chamber apical view; potentially, assessing also LA segments from the two-chamber apical view would have provided more comprehensive information for atrial function characterization, and also the analysis of reservoir and conduit function. Additionally, speckle tracking derived values of strain and strain rate may be slightly underestimated because of the elevated heart rate at higher exercise intensities.

Another consideration to interpret our data is that reservoir and conduit function during exercise were not analyzed. These concepts might help for a better understanding of atrial changes in this population. However, they do not consist in the most predominant change observed during effort, which was the active phase.

Finally, our population of athletes was small in comparison with other studies in the field (D'Andrea, 2010); this issue might partially influence the conclusions from the subgroup analysis, but is strong enough for raising our primary hypothesis. 


\section{Perspective}

To our knowledge this is the first study reporting atrial performance during exercise in athletes, demonstrating the expected increase in atrial contractile function that contributes to the increased cardiac output demand and to functional capacity. Importantly, we identified a subgroup of athletes with potential atrial dysfunction and adverse remodeling that might identify a subgroup with a different atrial behavior. Moderate aerobic sport is essential for cardiovascular health (Biswas,2015), but an excessive program training for a single subject potentially could lead to an adverse cardiac remodeling process.

\section{Acknowledgements}

This work was partially funded by: the Subprograma de Proyectos de Investigación en Salud - Instituto de Salud Carlos III, Spain (FIS - PI11/01709); the European Union 7th Framework Program (VP2HF FP7-2013611823); and the Comisión Nacional de Ciencia y Tecnologia (CONICYT), Chile (FONDAP 15130011).

\section{Competing interests}

Authors have nothing to disclose 


\section{References}

1. Abdulla J, Rokkedal J. Is the risk of atrial fibrillation higher in athletes than in the general population? A systematic review and meta-analysis. Europace 2009:11:1156-1159.

2. Behar V, Adam D, Lysyansky P, Friedman Z. The combined effect of nonlinear filtration and window size on the accuracy of tissue displacement estimation using detected echo signals. Ultrasonics 2004:41:743-753.

3. Benito B, Gay-Jordi G, Serrano-Mollar A, Guasch E, Shi Y, Tardif JC, Brugada J, Nattel S, Mont L. Cardiac arrhythmogenic remodeling in a rat model of long-term intensive exercise training. Circulation 2011:123:13-22.

4. Bijnens BH, Cikes M, Butakoff $C$, Sitges M, Crispi F. Myocardial motion and deformation: What does it tell as and How does it relate to function?. Fetal Diag Ther 2012:32:5-16.

5. Biswas A, Oh PI, Faulkner GE, Bajaj RR, Silver MA, Mitchell MS, Alter DA. Sedentary time and its time association with risk for disease incidence, mortality, and hospitalization in adults: a systematic review and meta-analysis. Ann Intern Medicine 2015:162:123-132.

6. Brugger $N$, Krause R, Carlen F, Rimensberger $C$, Hille R, Steck H, Wilhelm M, Seiler C. Effect of lifetime endurance training on left atrial mechanical function and on the risk of atrial fibrillation. Int J Cardiol 2014:170:419-25.

7. D'Andrea A, Caso P, Romano S, Scarafile R, Cuomo S, Salerno G, Riegler L, Limongelli G, Di Salvo G, Romano M, Liccardo B, lengo R, Ascione L, Del Viscovo L, Calabro P, Calabro R. Association between left atrial myocardial function and exercise capacity in patients with either idiopathic or ischemic dilated cardiomyopathy: a two-dimensional speckle strain study. Int J Cardiol 2009:132:354-63.

8. D'Andrea A, Riegler L, Cocchia R, Scarafile R, Salerno G, Gravino R, Golia E, Vriz O, Citro R, Limongelli G, Calabrio P, Di Salvo G, Caso P, Russo MG, Bossone E, Calabro R. Left atrial volume index in highly trained athletes. Am Heart J 2010:159:1155-61. 
9. D’Ascenzi F, Cameli M, Zacá V, Lisi M, Santoro A, Causarano A, Mondillo S. Supernormal diastolic function and role of left atrial myocardial deformation analysis by 2D speckle tracking echocardiography in elite soccer players. Echocardiography 2011:28:320-6

10. D’Ascenzi F, Cameli M, Padeletti M, Lisi M, Zaca V, Natali B, Malandrino A, Alvino F, Morelli M, Vasallo GM, Meniconi C, Bonifazi M, Causarano A, Mondillo S. Characterization of right atrial function and dimensión in top-level athletes: a speckle tracking study. Int J Cardiovasc Imaging 2013:29:87-94.

11. Di Martino E, Bellini C, Schwartzman D. In vivo porcine left atrial wall stress: Effect of ventricular tachypacing on spatial and temporal stress distribution. Journal of Biomechanics 2011:44:27552760.

12. Erol MK, Karakelleoglu S. Assessment of right heart function in the athletes heart. Heart Vessels 2002:16:175-80.

13. Gabrielli L, Bijnens BH, Butakoff C, Duchateau N, Montserrat S, Merino B, Gutierrez J, Paré C, Mont L, Brugada J, Sitges M. Atrial functional and geometrical remodeling in highly trained male athletes: for better or worse? Eur J Appl Physiol 2014:114:1143-1152.

14. Gabrielli L, Corbalan R, Córdova S, Enríquez A, McNab P, Verdejo HE, Godoy I, Zalaquet R, Lavandero S. Left Atrial Dysfunction Is a Predictor of Postcoronary Artery Bypass Atrial Fibrillation: Association of Left Atrial Strain and Strain Rate Assessed by Speckle Tracking. Echocardiography 2011:28:1104-8.

15. Gabrielli L, Enríquez A, Córdova S, Yañez F,Godoy I, Corbalán R. Assessment of left atrial function in hypertrophic cardiomyopathy and athlete's heart: a left atrial myocardial deformation study. Echocardiography 2012:29:943-9.

16. Kusunose K, Motoki H, Popovic ZB, Thomas JD, Klein AL, Marwick TH. Independent association of left atrial function with exercise capacity in patients with preserved ejection fraction. Heart 2012:98:1311-17. 
17. La Gerche A, Burns AT, Mooney DJ, Inder WJ, Taylor AJ Bogaert J, Macisaac Al, Heidbuchel H, Prior DL. Exercise-induced right ventricular dysfunction and structural remodeling in endurance athletes. Eur Heart J 2012:33:998-1006.

18. Lang RM, Bierig M, Devereux RB, Flachskampf FA, Foster E, Pellika PA, Picard MH, Roman MJ, Seward J, Shanewise J, Solomon S, Spencer KT, St John Sutton M, Stewart W. Recommendations for chamber quantification. Eur J Echocardiodr 2006:7:79-108.

19. Lang RM, Badano L, Mor-Avi V, Afilalo J, Armstrong A, Ernande L, Flachskampf F, Foster E, Goldstein S, Kuznetsova T, Lancelotti P, Muraru D, Picard MH, Rietzschel ER, Rudski L, Spencer KT, Tsang W, Voigt JU. Recommendations for Cardiac Chamber Quantification by Echocardiography in Adults: An Update from the American Society of Echocardiography and the European Association of Cardiovascular Imaging. J Am Soc Echocardiogr 2015:28:1-39

20. McClein G, George K, Lord R, Utomi V, Jones N, Somauroo J, Fletcher S, Oxborough D (2014). Chronic adaptation of atrial structure and function in elite male athletes. Eur Heart J: CardiovasC Imaging 2015:16:417-22.

21. Marciniak A, Claus P, Sutherland GR, Marciniak M, Baltabaeva A, Merli E, Bijnens B, Jahangiri M. Changes in systolic left ventricular function in isolated mitral regurgitation. A strain rate imaging study. Eur Heart J 2007:28:2627-36.

22. Margreet A, Maass A, Oberdorf-Maass S, Van Veldhuisen D, Van Gilst W, Van Gelder I. Mechanisms of atrial structural changes caused by stretch occurring before and during early atrial fibrillation. Cardiovascular Research 2010:89:754-65.

23. Molina L, Mont L, Marrugat J, Berruezo A, Brugada J, Bruguera J, Rebato C, Elosua R. Long term endurance sport practice increases the incidence of lone atrial fibrillation in men: a follow up study. Europace 2008:10:618-23.

24. Mont L, Elousa R, Brugada J. Endurance sport practice as a risk factor for atrial fibrillation and atrial flutter. Europace 2009:11:11-17. 
25. Mont L, Tamborero D, Elosua R, Molina I, Coll-Vinent B, Sitges M, Vidal B, Scalise A, Tejeira A, Berruezo A, Brugada J. Physical activity, height, and left atrial size are independent risk factors for lone atrial fibrillation in middle-aged healthy individuals. Europace 2008:10:15-20.

26. Naoum C, Falk GL, Ng AC, Lu T, Ridley L, Ing AJ, Kritharides L, Yiannikas J. Left atrial compression and the mechanism of exercise impairment in patients with a large hiatal hernia. J Am Coll Cardiol 2011:58:1624-34.

27. O'Keefe JH, Patil HR, Lavie CJ, Magalski A, Vogel R, McCullough PA. Potential adverse cardiovascular effects from excessive endurance exercise. Mayo Clin Proc 2012:87:587-95.

28. Padeletti M, Cameli M, Lisi M, Malandrino A, Zacá V, Montillo S. Reference values of right atrial longitudinal strain imaging by two-dimensional speckle tracking. Echocardiography 2012:29:14752.

29. Pelliccia A, Maron BJ, Di Paolo FM, Biffi A, Quattrini FM, Pisicchio C, Roselli A, Caselli A, Culasso F. Prevalence and clinical significance of left atrial remodeling in competitive athletes. J Am Coll Cardiol 2005:46:690-6.

30. Pluim BM, Zwinderman AH, van der Laarse A, Van der Wall EE. The athlete's heart: a meta-analysis of cardiac structure and function. Circulation 2000:101:336-344.

31. Rimbaş RC, Vinereanu D. Left atrial phasic strain, strain rate and velocity by speckle tracking echocardiography: normal values and effects of aging in a large group of normal subjects - Our reply. Int J Cardiol 2014:174:219-222.

32. Saraiva RM, Demirkol S, Buakhamsri A, Greenberg N, Popovic ZB, Thomas JD, Klein AL. Left atrial strain measured by two-dimensional speckle tracking represents a new tool to evaluate left atrial function. J Am Soc Echocardiogr 2010:2:172-80.

33. Schneider C, Malisius R, Krause K, Lampe F, Bahlmann E, Boczor S. Strain rate imaging for functional quantification of the left atrium: atrial deformation predicts the maintenance of sinus rhythm after catheter ablation of atrial fibrillation. Eur Heart J 2008:20:1397-1409. 
34. Tsai CT, Tseng CD, Hwang JJ, Wu CK, Yu CC, Wang YC, Chen WP, Lai LP, Chiang FT, Lin JL. Tachycardia of atrial myocites induces collagen expression in atrial fibroblasts through transforming growth factor B1. Cardiovascular Research 2011:89:805-815.

35. Van Buuren F, Mellwig KP, Faber L, Prinz C, Fruend A, Dahm JB, Kottmann T, Bogunovic N, Horstkotte D, Butz T, Langer C. The occurrence of atrial fibrillation in former top-level handball players above the age of 50. Acta Cardiol 2012:67:213-220.

36. Vaturi M, Hadar T, Yedidya I, Shapira Y, Monakier D, Weisenberg DE, Sagie A. The association of left atrial volume with exercise capacity in patients with chronic severe mitral regurgitation. Isr Med Assoc J 2010:12:150-3.

37. Voeller RK, Aziz A, Maniar HS, Ufere NN, Taggar AK, Bernabe NJ, Cupps BP, Moon MR. Differential modulation of right ventricular strain and right atrial mechanics in mild vs severe pressure overload. Am J Physiol Heart Circ Physiol 2011:301:2362-2371.

38. Wilhelm M, Roten L, Tanner H, Schmid JP, Wilhelm I, Saner H. Long-term cardiac remodeling and arrhythmias in nonelite marathon runners. Am J Cardiol 2012:110:1060-65. (a)

39. Wilhelm M, Zueger T, De Marchi S, Rimoldi SF, Brugger N, Steiner R, Stettler C, Nuoffer JM, Seiler C, Ith M. Inflammation and atrial remodeling after a mountain marathon. Scand J Med Sci Sports 2012:24:519-525.(b)

40. Wilhelm M, Nuoffer JM, Schmid JP, Wilhelm I, Saner H. Comparision of pro-atrial natriuretic peptide and atrial remodeling in marathon versus non-marathon runners. Am J Cardiol 2012:109:1060-65.(c) 
Table 1. Hemodynamic and ventricular characteristics of athletes and controls

\begin{tabular}{|c|c|c|c|c|c|c|}
\hline & \multicolumn{3}{|c|}{ Baseline } & \multicolumn{3}{|c|}{ Peak Exercise } \\
\hline & $\begin{array}{l}\text { Athletes } \\
(n=50)\end{array}$ & $\begin{array}{l}\text { Controls } \\
(n=30)\end{array}$ & p & $\begin{array}{l}\text { Athletes } \\
(n=50)\end{array}$ & $\begin{array}{l}\text { Controls } \\
(n=30)\end{array}$ & $\mathbf{P}$ \\
\hline Heart Rate (bpm) & $59 \pm 9$ & $69 \pm 12$ & $<0.01$ & $156 \pm 139$ & $156 \pm 9 \ddagger$ & NS \\
\hline Systolic BP (mmHg) & $125 \pm 9$ & $119 \pm 6$ & $<0.01$ & $198 \pm 179$ & $191 \pm 20 \ddagger$ & NS \\
\hline Diastolic BP (mmHg) & $79 \pm 4$ & $77 \pm 4$ & NS & $81 \pm 39$ & $80 \pm 5 \wedge$ & NS \\
\hline Maximum load (Watts) & - & - & - & $224 \pm 38$ & $169 \pm 26$ & $<0.01$ \\
\hline METs & - & - & - & $11.4 \pm 1.6$ & $8.8 \pm 1.3$ & $<0.01$ \\
\hline $\begin{array}{l}\text { Estimated } \mathrm{O}_{2} \text { consumption } \\
(\mathrm{mL} / \mathrm{kg} / \mathrm{min})\end{array}$ & - & - & - & $40 \pm 5.6$ & $31 \pm 4.6$ & $<0.01$ \\
\hline LV Cardiac Index $\left(I / \mathrm{min} / \mathrm{m}^{2}\right)$ & $2.52 \pm 0.63$ & $2.53 \pm 0.44$ & NS & $8.33 \pm 3.189$ & $7.04 \pm 1.24 \ddagger$ & 0.02 \\
\hline LVEF (\%) & $61 \pm 5$ & $61 \pm 5$ & NS & $68 \pm 59$ & $66 \pm 3 \ddagger$ & NS \\
\hline $\begin{array}{l}\text { LV end-diastolic volume } \\
\text { index }\left(\mathrm{mL} / \mathrm{m}^{2}\right)\end{array}$ & $60.9 \pm 12.2$ & $45.9 \pm 6.9$ & $<0.01$ & $51.3 \pm 10.79$ & $38.9 \pm 7.4 \ddagger$ & $<0.01$ \\
\hline $\begin{array}{l}\text { LV end-systolic volume index } \\
\left(\mathrm{mL} / \mathrm{m}^{2}\right)\end{array}$ & $24.0 \pm 4.3$ & $19.0 \pm 4.9$ & $<0.01$ & $16.0 \pm 4.29$ & $12.8 \pm 3.1 \ddagger$ & $<0.01$ \\
\hline RV end-diastolic area $\left(\mathrm{cms}^{2}\right)$ & $26.7 \pm 4.7$ & $20.2 \pm 4.4$ & $<0.01$ & $23.4 \pm 4.4$ ๆ & $17.1 \pm 4.6 \ddagger$ & $<0.01$ \\
\hline RV end-systolic area $\left(\mathrm{cm}^{2}\right)$ & $13.3 \pm 2.8$ & $10.1 \pm 2.2$ & $<0.01$ & $11.1 \pm 2.4$ ๆ & $8.3 \pm 3.0 \ddagger$ & $<0.01$ \\
\hline RV fractional area change (\%) & $49 \pm 6$ & $49 \pm 7$ & NS & $52 \pm 69$ & $51 \pm 7$ & NS \\
\hline
\end{tabular}

ๆ $p<0.05$ versus athletes at baseline; $\ddagger p<0.05$ versus controls at baseline.

Abbreviations: BP: blood pressure; LV, left ventricle; LVEF: LV ejection fraction; RV, right ventricle; NS, not significant $(p \geq 0.05)$ 
Table 2. Atrial size and function at baseline and during exercise.

\begin{tabular}{|c|c|c|c|c|c|c|}
\hline & \multicolumn{3}{|c|}{ Baseline } & \multicolumn{3}{|c|}{ Peak Exercise } \\
\hline & $\begin{array}{l}\text { Athletes } \\
(n=50)\end{array}$ & $\begin{array}{l}\text { Controls } \\
(n=30)\end{array}$ & $\mathbf{p}$ & $\begin{array}{l}\text { Athletes } \\
(n=50)\end{array}$ & $\begin{array}{l}\text { Controls } \\
(n=30)\end{array}$ & $\mathbf{p}$ \\
\hline \multicolumn{7}{|l|}{ Left atrium } \\
\hline Area $\left(\mathrm{cm}^{2}\right)$ & $18.0 \pm 3.6$ & $14.5 \pm 2.3$ & $<0.01$ & $15.7 \pm 3.79$ & $12.7 \pm 2.5 \ddagger$ & $<0.01$ \\
\hline Maximum Volume (mL) & $55.9 \pm 17.5$ & $36.1 \pm 8.8$ & $<0.01$ & $43.3 \pm 18.79$ & $29.4 \pm 8.3 \ddagger$ & $<0.01$ \\
\hline $\begin{array}{l}\text { BSA Indexed Maximum Volume } \\
\left(\mathrm{mL} / \mathrm{m}^{2}\right)\end{array}$ & $29.4 \pm 9.2$ & $18.6 \pm 4.1$ & $<0.01$ & $22.7 \pm 10.29$ & $15.0 \pm 4.0 \ddagger$ & $<0.01$ \\
\hline Pre- $\mathrm{P}$ wave volume $(\mathrm{mL})$ & $28.5 \pm 10.5$ & $19.1 \pm 5.0$ & $<0.01$ & $23.4 \pm 8.79$ & $15.6 \pm 4.2 \ddagger$ & $<0.01$ \\
\hline Minimum volume $(\mathrm{mL})$ & $19.4 \pm 8.8$ & $11.9 \pm 4.6$ & $<0.01$ & $10.7 \pm 7.69$ & $5.6 \pm 2.8 \ddagger$ & $<0.01$ \\
\hline Active emptying volume $(\mathrm{mL})$ & $9.0 \pm 1.2$ & $7.1 \pm 2.8$ & $<0.01$ & $12.6 \pm 2.79$ & $9.9 \pm 2.1 \ddagger$ & $<0.01$ \\
\hline Active emptying volume $\left(\mathrm{mL} / \mathrm{m}^{2}\right)$ & $4.7 \pm 1.4$ & $3.7 \pm 0.7$ & $<0.01$ & $6.6 \pm 1.39$ & $5.1 \pm 1.0 \ddagger$ & $<0.01$ \\
\hline Active emptying fraction & $0.34 \pm 0.09$ & $0.39 \pm 0.09$ & 0.01 & $0.59 \pm 0.14$ & $0.65 \pm 0.09$ & 0.02 \\
\hline LASa (\%) & $-12.7 \pm 1.9$ & $-11.7 \pm 2.5$ & NS & $-21.4 \pm 5.39$ & $-24.0 \pm 4.6 \ddagger$ & 0.04 \\
\hline $\operatorname{LASRa}\left(\mathrm{s}^{-1}\right)$ & $-1.57 \pm 0.42$ & $-1.58 \pm 0.51$ & NS & $-2.85 \pm 1.869$ & $-3.34 \pm 0.85 \ddagger$ & 0.04 \\
\hline \multicolumn{7}{|l|}{ Right atrium } \\
\hline Area $\left(\mathrm{cm}^{2}\right)$ & $18.9 \pm 4.0$ & $15.2 \pm 2.2$ & $<0.01$ & $17.2 \pm 3.8 \pi$ & $13.5 \pm 2.3 \ddagger$ & $<0.01$ \\
\hline Maximum Volume (mL) & $65.1 \pm 20.7$ & $43.8 \pm 10.2$ & $<0.01$ & $54.7 \pm 20.99$ & $34.5 \pm 9.3 \ddagger$ & $<0.01$ \\
\hline $\begin{array}{l}\text { BSA Indexed maximum Volume } \\
\left(\mathrm{mL} / \mathrm{m}^{2}\right)\end{array}$ & $34.1 \pm 10.9$ & $22.6 \pm 4.7$ & $<0.01$ & $28.6 \pm 10.79$ & $17.8 \pm 4.6 \ddagger$ & $<0.01$ \\
\hline Pre-P wave volume (mL) & $43.2 \pm 14.5$ & $27.6 \pm 8.0$ & $<0.01$ & $32.5 \pm 12.29$ & $22.0 \pm 7.8 \ddagger$ & $<0.01$ \\
\hline Minimum volume $(\mathrm{mL})$ & $34.8 \pm 14.2$ & $20.3 \pm 7.7$ & $<0.01$ & $20.6 \pm 12.89$ & $10.6 \pm 5.8 \ddagger$ & $<0.01$ \\
\hline Active emptying volume $(\mathrm{mL})$ & $8.4 \pm 1.9$ & $7.3 \pm 1.4$ & 0.01 & $11.9 \pm 2.69$ & $11.4 \pm 3.2 \ddagger$ & NS \\
\hline Active emptying volume $\left(\mathrm{mL} / \mathrm{m}^{2}\right)$ & $4.4 \pm 0.9$ & $3.8 \pm 0.7$ & $<0.01$ & $6.2 \pm 1.49$ & $5.9 \pm 1.6 \ddagger$ & NS \\
\hline Active emptying fraction & $0.22 \pm 0.07$ & $0.28 \pm 0.08$ & $<0.01$ & $0.41 \pm 0.19$ & $0.53 \pm 0.1 \ddagger$ & $<0.01$ \\
\hline RASa (\%) & $-11.9 \pm 1.7$ & $-12.4 \pm 2.7$ & NS & $-19.2 \pm 5.89$ & $-22.5 \pm 3.4 \ddagger$ & 0.01 \\
\hline $\operatorname{RASRa}\left(s^{-1}\right)$ & $-1.52 \pm 0.44$ & $-1.57 \pm 0.55$ & NS & $-2.13 \pm 1.099$ & $-2.51 \pm 1.08 \ddagger$ & NS \\
\hline
\end{tabular}

ๆ $p<0.01$ versus athletes at baseline; $\ddagger p<0.01$ versus controls at baseline.

Abbreviations: BSA: body surface area; LASa, LA late diastolic (atrial contraction) peak negative strain; LASRa: LA late diastolic (atrial contraction) peak negative strain rate; RASa, RA late diastolic (atrial contraction) peak negative strain; RASRa, RA late diastolic (atrial contraction) peak negative strain rate. 
Figure Legends

Figure 1. Left atrial strain curves of a given subject at rest (Panel A) and during exercise (Panel B). Arrows indicate the peak negative left atrial strain during active atrial.

Figure 2. Scatterplot of individual changes in the active LA/RA deformation with exercise in athletes (blue) and controls (red). Each line links baseline (dot symbol) and exercise (cross symbol) values for a given individual. The subgroup with significant atrial dilatation according to the indexed atrial volume is also indicated. LASa: LA late diastolic (atrial contraction) peak negative strain; LASRa: LA late diastolic (atrial contraction) peak negative strain rate; RASa, RA late diastolic (atrial contraction) peak negative strain; RASRa, RA late diastolic (atrial contraction) peak negative strain rate.

Figure 3. Changes in atrial contractile function with exercise in athletes with significant (atrial volume $\geq 40 \mathrm{~mL} / \mathrm{m}^{2}$ ) or athletes with non-significant atrial dilatation (atrial volume $<40 \mathrm{~mL} / \mathrm{m}^{2}$ ). Left and right panels correspond to the LA and RA measurements, respectively. LASa: LA late diastolic (atrial contraction) peak negative strain; LASRa: LA late diastolic (atrial contraction) peak negative strain rate; RASa, RA late diastolic (atrial contraction) peak negative strain; RASRa, RA late diastolic (atrial contraction) peak negative strain rate.

Figure 4. Contribution of LA contractile function to exercise capacity. Scatterplots of the relationship between LA rest and exercise active emptying volume and metabolic equivalents (METS) reached in the stress test.

Figure 5. Bland-Altman plots for the intra-observer reproducibility of Sa and SRa measurements of the LA and RA, at rest (top) and during exercise (bottom). Values are expressed as mean differences and 95\% confidence intervals (\% for Sa and s ${ }^{-1}$ for SRa). 
Figure 6. Bland-Altman plots for the inter-observer reproducibility of Sa and SRa measurements of the LA and RA, at rest (top) and during exercise (bottom). Values are expressed as mean differences and $95 \%$ confidence intervals (\% for Sa and $\mathrm{s}^{-1}$ for SRa). 
Figure 1

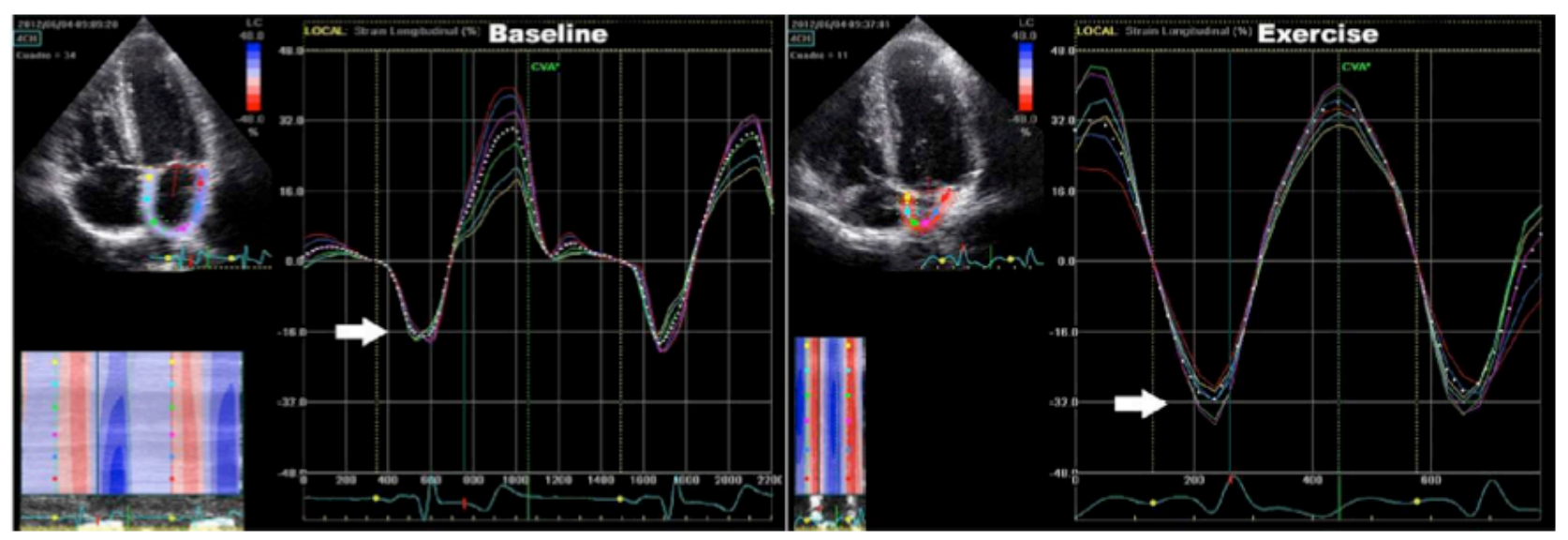


Figure 2

A
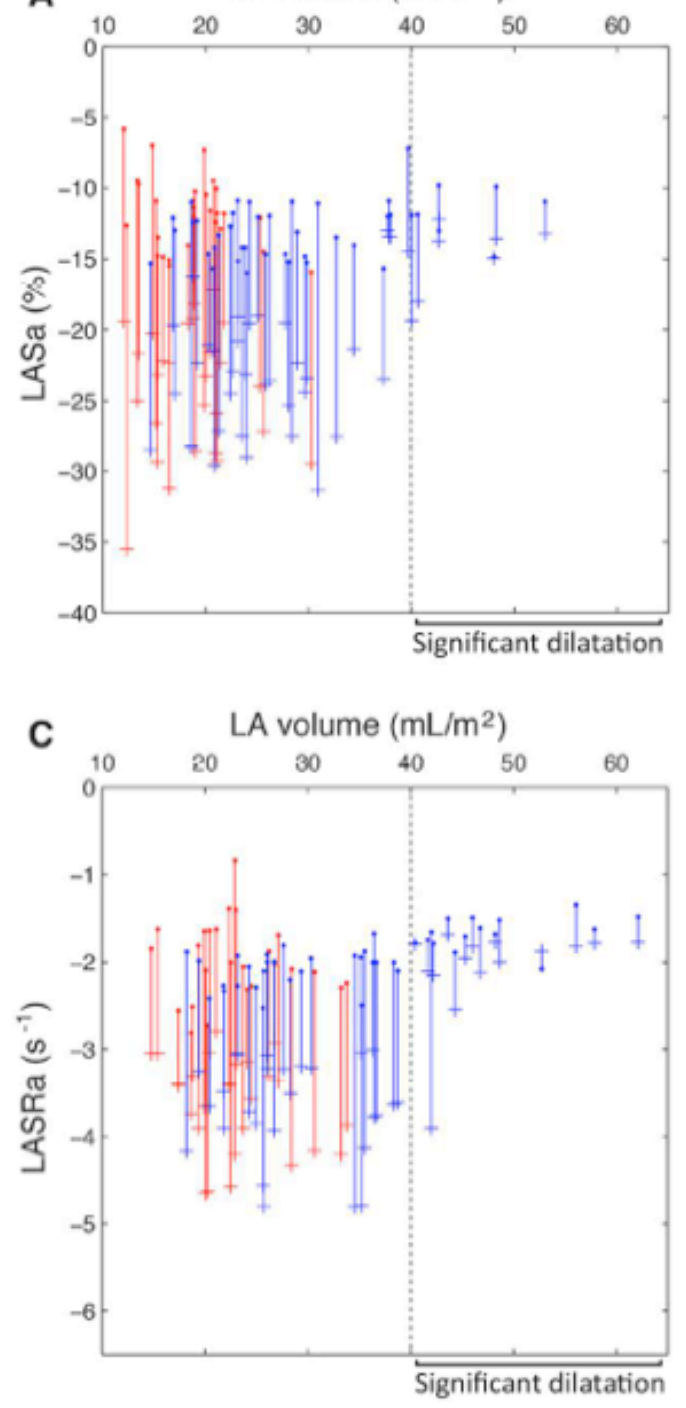

B RA volume $\left(\mathrm{mL} / \mathrm{m}^{2}\right)$

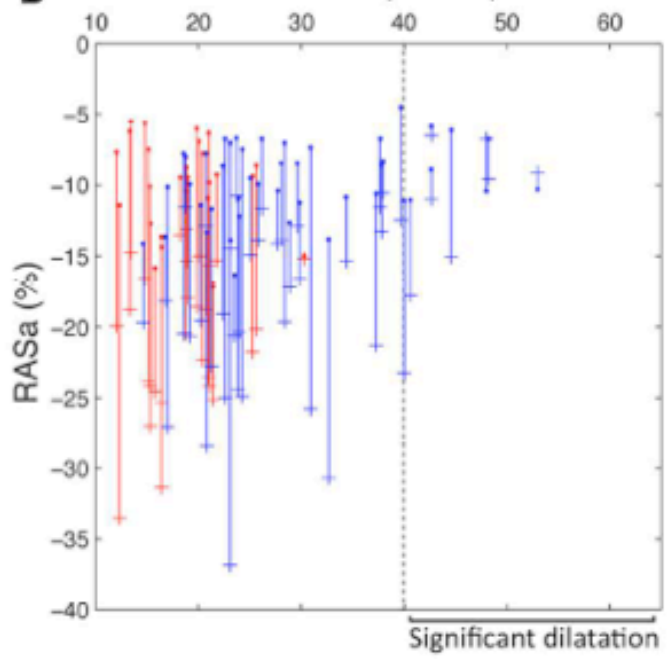

- Rest

+ Exercise

- Control

- Athlete

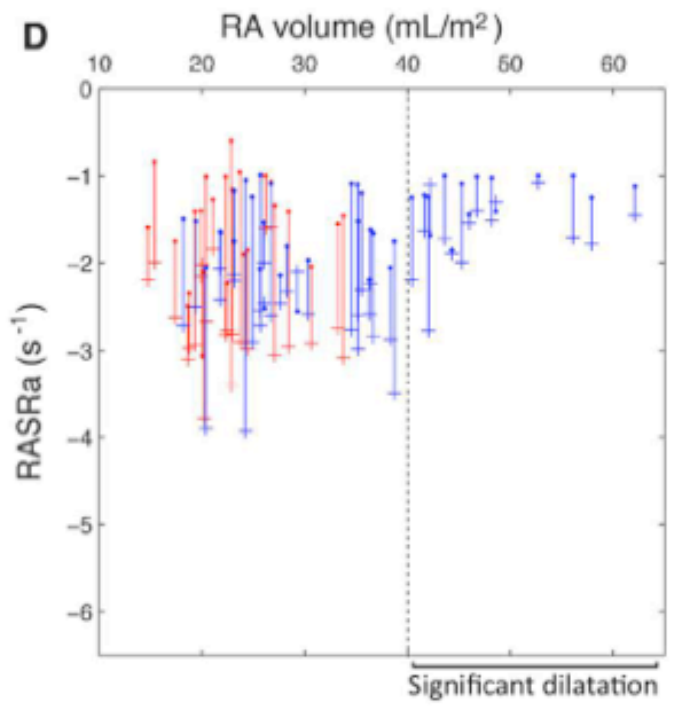


Figure 3
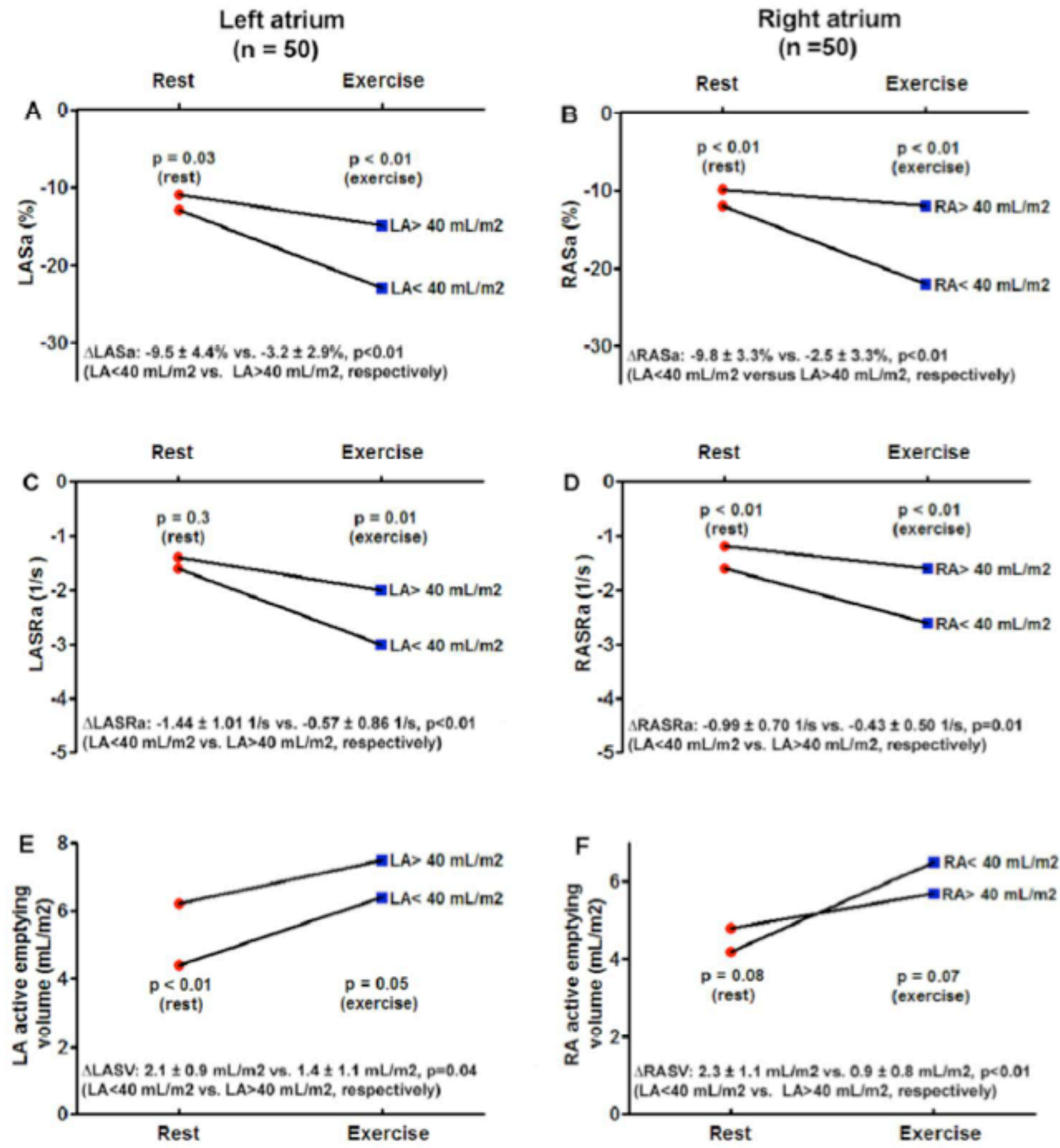
Figure 4
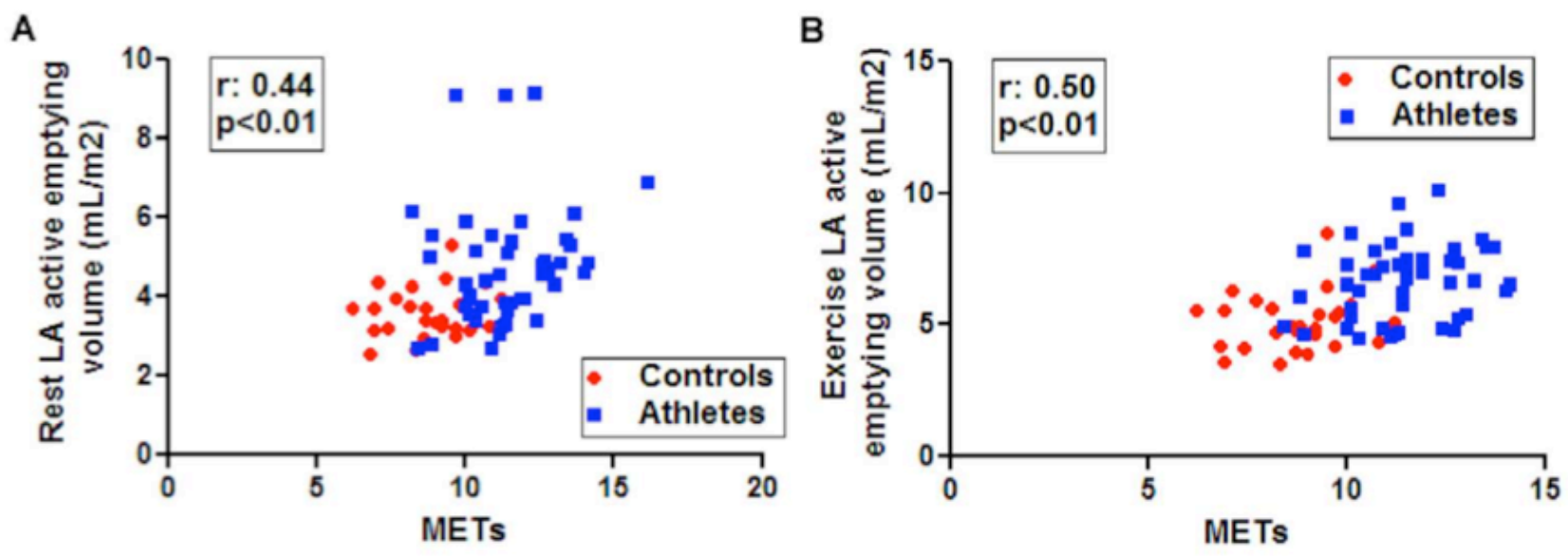
Figure 5
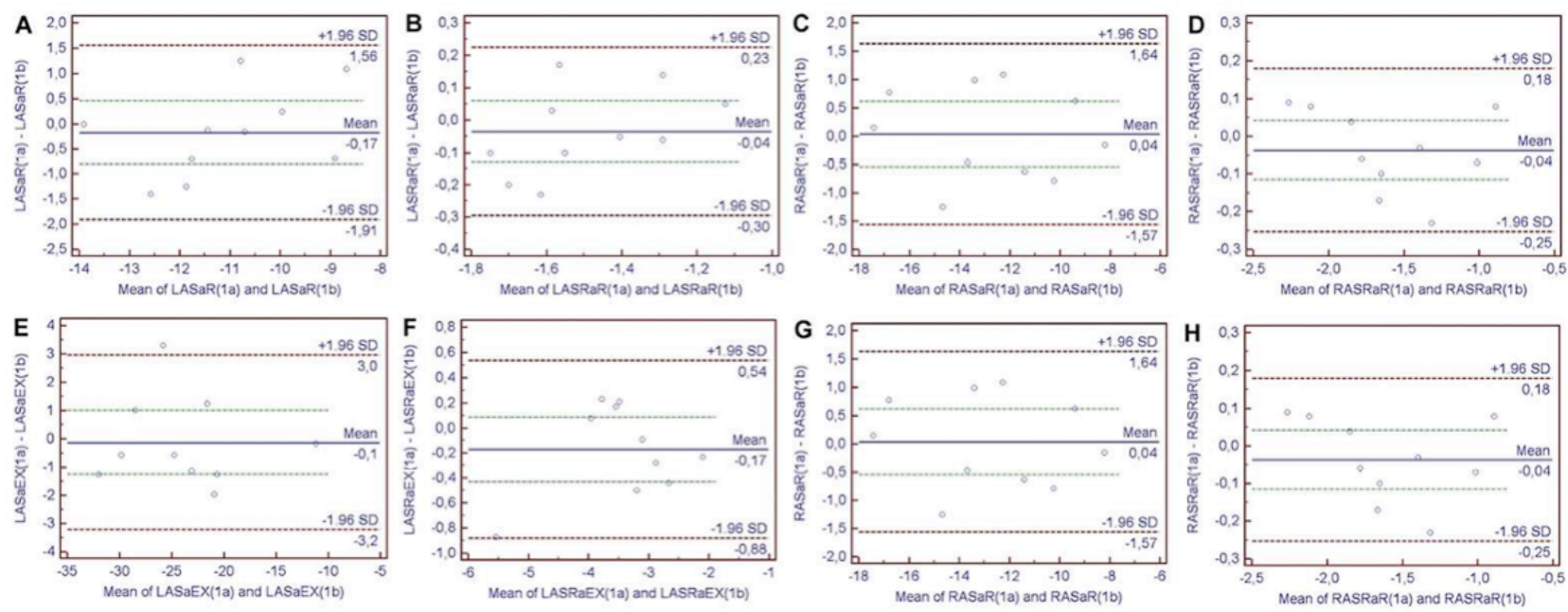
Figure 6
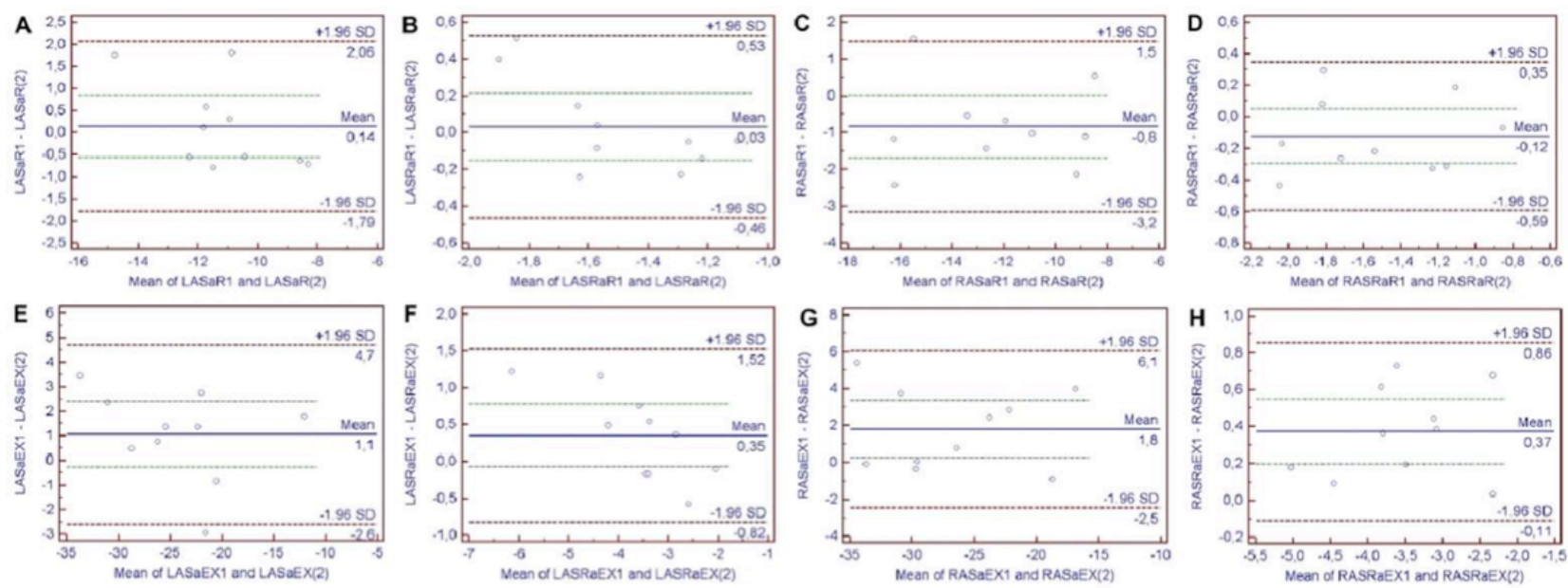